\title{
La técnica constitucional de la autonomía (*)
}

\author{
Antonio La Pergola
}

\begin{abstract}
COMO ES SABIDO, el importante y siempre actual problema de las autonomias territoriales es común a la experiencia democrática de Italia y España. La idea de la región para no complicar la perspectiva me detendré en este nivel de entes autónomos- fue introducida on la Constitución italiana por legisladores que, si bien mancjaron varias fuentes, se inspiraron sobre todo en el ordenamiento do la Segunda República espaǹola, en el que aquélla recibió una primera y sugestiva actuación. Estos mb́mos institutos de la descentralización reaparecen hoy en el vigente orden politico de Espana, después de que su funcionamiento haya cono. cido en Italia el transcurso de un treintenio. Esta circunstancia me permite dedicar alganas reflexiones a este tema que espero puedan ser de alguna utilidad para los estudiosos del ordenamiento espanol.
\end{abstract}

Bien entendido que con esto no pretendo ignorar que entre la región italiana y la comunidad trufónoma -como se dice entre ustedes existen diferencias en mats de un aspecto en fo relativo a las competencias y a su respectiva posición en el sistema constitucional Al contrario, en Espaĩa aparece, ante todo, una nueva denominación del ente, dato éste que no carece de importancia. En efecto, la noción de comunidad se utiliza en

(*) Traducción de Pablo Lucas 3 furillo de la Cueva 
d lenguaje cientifico y en los propios textos normativos cuando se trata de describir estructuris concebidas fuera de los esquemas habituales, especialmente en el plano en el que se confunden el Estado federal y las Uniones de Estados. Baste pensar en las comunidades europeas o, incluso, remontándonos más hacia atrás en el curso de la historia contemporánea, en las diversas vicisitudes del término "commonwealth", adoptado en el mundo de la lengua inglesa para designar la evanescente y heterogénea agrupación de naciones que queda todavia como residuo del antiguo imperio británico. Igualmente, podemos recordar la situación de algunos miembros (Massachtissets) o la de comunidades territoriales asociadas (Puerto Rico) a la federación estadounidense. Desconozco y no puedo indaf rlo en esta sede, hasta qué punto la fórmula de ta "comunidad autónoma" is fruto, en el vigente texto fundamental español, de una opción consciente del constituyente: en efecto, esa expresión sirve deliberadamente para abrir a los nuevos entes autónomos recursos institucionales mis vastos, al reenviar el desarrollo del régimen de autonom ía a las leyes organicas. Tampoco sabría decir si se ha querido alumbrar una configuración espacial de las comunidades que tenga en cuenta los factores subyacentes a la autonomia como, por ejemplo, la persistente traza o coincidencia de individualidades nacionales (después conducidas a la unidad en el marco estatal) o, incluso, las necesidades, actuales o futuras, de las colectividades interesadas. Como quiera que sea, el término "región" no posee una gama tan amplia de implicaciones. $Y$ a estos efectos, no importa que se trate de la mancomunidad de provincias que preveía la Constitución española de 1931 o de la actual región italiana, bien de estatuto ordinario, bien de estatuto especial : pues casi siempre es of resultado mecánico del mantenimiento de preexistentes y ya supcradas divisiones administrativas del Estado. Mis en general, se podria decir que el uso del vocablo "región", en el constitucionalismo que no es familiar. excluye la cualidad de Estado del ente autónomo y la estructura federal del Estado central. En cambio, el otro término, "comunidad", es menos comprometido y deja abierta la posibilidad de que el sistema de lis autonomías se desarrolle de forma original superando el rígido esquema de la dicotomia Estado federal-Estado unitario descentralizado. Ciertamente, la adopción de una expresión en lugar de la otra es un simple indice de la sustancia del fenómeno y sólo un elemento de la correspondiente definición conceptual que debe resultar del atento y profundo análisis del texto y de la realidad constitucional. Por mi parte, no me propongo llevar a cabo un estudio de ese tipo en esta ocasión ni, mucho menos, una comparación de los ordenamientos español e italiano; intento que, a mi juicio, es toda. vía prematuro por la falta de material empirico que debe constituir el necesario soporte de la investigación. 
Me limitaré, por el contrario, a una rápida reseña de los problemas que conciernen, en general, a la técnica constitucional de la autonomía. Para ello, recogeré buena parte de mis observaciones de la exposición que, en su tiempo, realicé ante la Comisión de Asuntos Regionales del Parlamento italiano con motivo de una audiencia cognoscitiva. Ante todo, he de advertir que el estudio está "fechado". Se remonta a poco después de la institución de las regiones ordinarias, verificada con notable retraso respecto a los comienzos del experimento autonómico en las islas y en las áreas fronterizas que gozan de estatutos especiales. No obstante, me parece que, precisamente, este momento histórico de la evolución constifucional de mi pa is puede ser aqui de algun interés. En efecto, en aquellos años se difundio el interés por las autonomías que ya había advertido, con viva y madura sensibilidad hacia los sistemas extranjeros, la opinión cientifica y la política italiana en la época de la Asamblea Constituyente. De esta manera, se produjo un clima en cierta medida anílogo al de la España actual que atraviesa una fase creativa en que se va plasmando la constitucion viviente. Por lo demás, siempre he procurado tomar en consideración esta problemática, aun en los casos en que se refiere más directamente al ordenamiento italiano, desde la perspectiva del derecho comparado. Esta circunstancia explica también el porqué de mi decisión de volver a proponer mi punto de vista en esta ocasión.

Sin embargo, he de hacer una advertencia más en relación con las observaciones que he hecho sobre las posibilidades de aplicación de la noción de comunidad.

El regionalismo y ef federalismo son manifestaciones estructurales de una misma categoria: el Estado descentralizado. Manifestaciones diferentes pero con un necesario punto de encuentro que consiste en la garant fa ofrecida a la autonomía territorial por la Constitución rigida. Mis adelante, trataré de ilustrar este punto con algún ejemplo oportuno. No obstante, el mismo concepto de comunidad ayuda a ponerlo de manifiesto con nitidez; concepto que no por casualidad podemos vincular a la Región y al Estado miembro. En estos dos casos, hay un ente cuya autonomia está garantizada constitucionalmente. En escritos anteriores, traducidos tambièn en lengua espanola ("El empirismo en el estudio de los sistemas federales", en Revista de Estudios Politicos, número 188. págs. 21-79; "El caso italiano", en Federalismo y Regionalismo, Madrid 1979, págs. 167-190) he dado cuenta de estas afirmaciones. A ellos me remito. Aclararé, para mayor exactitud, por qué pueden considerarse equivalentes las garantias constitucionales mientras varia, en lo relativo a los tipos estructurales, la autonomía garantizada. 
Decía entonces que la autonomia garantizada al Estado miembro es residual, porque es caracteristica de un Estado inicialmente soberano; que, posteriormente, ha entrado a formar parte de una federación. En cambio, es "otorgada" la autonomía garantizada a una región que se instituye en un Estado anteriormente centralizado y con posterioridad subdividido en unidades autónomas. Dando por suptiesta esta distinción, enunciaré otra que se refiere únicamente a los Estados federales. La distinción entre Estado miembro y región se traza sobre la base de la génesis histórica de sus respectivos ordenamientos. La subdistinción de los sistemas federales, a la que ahora me refiero, deriva de los criterios que presiden el reparto del poder entre el centro de las unidades de la federación. El federalismo es entendido, en ocasiones, seguin aquella figura que la vieja doctrina definia como el Estado de Estados: en ella tenemos dos esferas -la del Estado central y la del Estado miembro- abarcando cada una todo el abanico de las funciones de una comunidad estatal: legislación, ejecución, jurisdicción. En este caso, la esfera de la unidad local - reducida y subordinada cuanto se quiera por el hecho de su pertenencia al Estado central-continúa siendo, desde el punto de vista de la plenitud estructural, la de un Estado. Igualmente completa es la cstructura del Estado central que. por su parte, necesita disponer en un complejo autónomo de órganos: parlamento, gobiemo y tribunales de justicia.

Es diferente aquella otra forma de federalismo que se inspira en $\mathrm{t}$ criterio de centralizar $-y$, correlativamente, descentralizar- una función determinada sin que ello afecte necesariamente al bloque de las funciones estatales en su totalidad. Es cierto que también aquí el Estado central es el único ente soberano, portador de un ordenamiento originario. Sin embargo, ts distinto, en relación con el caso antes considerado, el aparato estructural tanto de este ente central como de los entes territoriales menores que constituyen la unidad de la federación. La legislación, la ejecución y la jurisdicción pueden residir en el centro o, por el contrario, revertir a la periferia del sistema y convertirse, de este modo, en funciones pertenccientes únicamente a la federación o a una concreta unidad territorial. o bien a una y otra a la vez. Existe, al respecto, una gran variedad de soluciones que el constituyente formula y sistematiza racionalmente. No niego que, aun dentro de esta última clasificación, es necesario observar la raíz histórica del federalismo. Raiz que puede ser remota y colonial cuando estamos ante un federalismo que implica Estados miembros configurados cada uno como un microcosmos, con la estructura completa de una comunidad estatal que, si se mira hacia atrás, puede verse ya en embrión en el inicial status del ente, el de colonia, antes de la separación de la autoridad imperial y del paso al sistema federal, sobrevenido con la independencia de la madre patria. 
Por el contrario, se da un origen moderno y exquisitamente europeo del modelo federal cuando éste incide sobre cada función. La adopción de este ûltimo sistema ha estado vinculada, a menudo, a la exigencia de descentralizar ante todo la función administrativa. Esto ha supuesto, la mayoria de las veces, el mantenimiento y robustecimiento de la tradición de localismo administrativo; a lo que sigue la atribución al ente local de la autonomía legisiativa, pero muy raramente se le atribuye un propio orden judicial. Nuestra experiencia enseña que el paso de la autarquía a la autonomía es realmente más breve y menos difícil que el que conduce a la autotutela.

Ahora bien, la idea de la región tiene un hilo conductor: llega a la Constitución española de 1931 a través de una adaptación de modelos que se habian ensayado entre las dos guerras mundiales, en Austria y Alemania, a los que denominaré modelos de federalismo funcional - en el sentido antes indicado-para distinguirlos de la otra especie o estructura de Estados federales cuyo arquetipo es el federalismo integral del ordenamiento estadounidense. Por su parte, la región italiana y la comunidad autónoma española, el día de hoy, se inscriben en la línea de desarrollo que deriva del federalismo funcional.

He aquí, por tanto, el punto en el que el Estado federal y el Estado con autonomía regional tienen un parentesco e, incluso, una matriz estructural comun. El federalismo funcional sirve especialmente -decia más arriba - para la descentralización. $Y$ en nuestros dos ordenamientos, asi como en Austria, se ha đescentralizado la legislación; $y$, aún más, la administración pero no la función jurisdiccional. La distribución đel poder entre el Fstado y las unidades autónomas es diferente según las materias: pero, casi siempre, se encuadra en el esquema de las competencias concurrentes entendido ampiiamente. Este esquema encuentra en los sistemas del federalismo funcional una acogida más intensa que en los del otro tipo; ordenados, por lo general, sobre la nítida separación entre la esfera central y la local. No obstante, es cierto que desde el New Deal en adelante tambiên estos últimos sistemas tienden a perder su diseño lineal y evolucionan. si no en una dirección exactamente igual a la de los más complejos ordenamientos del federalismo funcional, si hacia una disciplina articulada de las relaciones y de las conexiones entre ordenamientos de cooperación de los miembros entre ellos y con la autoridad central. Tendencia que, por otra parte, no es extrana al federalismo funcional y se conoce como cooperative federalism. En conclusión, la distancia que separa federalismo y regionalismo se va acortando. En el esbozo que he trazado, el federalismo funcional representa un ărea intermedia $y$, por así decirlo. de paso 
entre el núcleo mas vetusto de los ordenamientos federales y el contexto de centralización en el que hoy pueden situarse las regiones italianas y las comunidades autónomas espanolas. Este preámbulo era indispensable para el correcto encuadramiento de las observaciones que siguen.

\section{II}

1.- Es necesario fijar la atención sobre un doble orden de problemas que revelan la importancia de cada sistema de autonomfas territoriales, precisamente desde la perspectiva de sus têtes de chapites: 1) por una parte, la distribución de los poderes; 2 ) por la otra, la cooperación de los poderes que se impone como una necesidad funcional, por no decir histórica, de los sistemas descentralizados, desde el momento en que el esquema de distribución trazado en el texto escrito de la Constitución es aplicado y ajustado a la realidad. Se trata, en definitiva, de dos aspectos de un mismo fenómeno. Los problemas conexos con la autonomía tributaria y con la organización de los poderes administrativos requeririan una investigación autónoma a desarrollar en otra sede.

2. - Es sabido que la téenica de la distribución de competencias es el problema central de la autonomía y, en todos los Estados modernos descentralizados, como el nuestro. tiene un significado en definitiva anàlogo al de la separación de poderes: si la separación de poderes es garantia del individuo, la distribución de competencias es garantia de la autonomia territorial.

A esto hay que añadir, yo diria que inevitablemente (con lo que tenemos otra tendencia recurrente), la necesidad de una u otra forma de control jurisdiccional y de la Constitución rigida. No existe un sistema de autonomfa sin algùn tipo de control jurisdiccional. Bien entendido que este control puede organizarse y ejercerse de diversas maneras. Las ùnicas excepciones a esta regla se han corregido casi siempre: por ejemplo, en la Alemania de Weimar faltaba un Tribunal Constitucional, pero su ausencia se suplió con la creación de un tribunal encargado de dirimir las controversias entre la federación y los Estados miembros.

Pero, precisamente por esto, porque la técnica de la distribución de competencias es el problema central de la autonomia, es también el problema más difícil. Repartir las competencias significa distribuirlas segùn las materias y según el territorio y es sabido que definir una materia en el texto de la Constitución o en el texto de la ley es, casi siempre, una tarea que escapa a las posibilidades del legislador y requiere el trabajo integrador 
del intérprete. Por ejempio, no se puede recurrir a la definición auténtica de las materias de competencia federal o de competencia local ni siquiera en aquellos ordenamientos en los que el legislador es llamado a ocuparse de los detalles, como sucede, por ejemplo, en los ordenamientos anglosajones en los que esta legislación de detalle se explica por la exigencia de derogar un fondo de normas consuetudinarias.

Ahora bien, tan pronto como nos disponemos a considerar los modelos ofrecidos por el derecho comparado, nosotros que vivimos y operamos dentro de un sistema regional, enseguida nos encontramos con dificultades. Fa cierto sentido, nuestro sistema regional es un unicum: en la Consituyente se dijo que es un cruce entre el Estado federal y el Estado unitario. Los modelos históricos que existían con anterioridad han desaparecido, en especial el de la Constitución española de 1931 que fue el que nuestro constituyente consideró más de cerca; ordenamiento avanzadisimo en la técnica de las competencias que prefigura muchas de las soluciones surgidas, mís tarde, en la experiencia del regionalismo italiano.

Por otra parte, es nuestro propio ordenamiento regional el que, en cierta manera, va suscitando la atención de los extranjeros. Hoy, en Europa, el problema del regionalismo se ha planteado en Bélgica, en Francia y en otros pa ises. En mayo de 1971, tuve la ocasión de reunirme con algunos expertos británicos en estas materias en la Universidad de Oxford. Se hablaba entonces, en Gran Bretana, de un sistema regional análogo al nuestro. El problema permanece todavia abierto y la experiencia italiana continúa despertando un gran interés.

Nuestro Estado regional se encuentra entre dos posibles líneas de desarrollo: por un lado, el Estado descentralizado que posee un pasado de centralización burocratica: por el otro, el Estado federal en el sentido pleno y caracteristico del término. Ahora bien, desde el enfoque que me he propuesto, son las técnicas del federalismo las que presentan un interés predominante. Quizís sea oportuno justificar esta afirmación. El federalismo se halla por doquier en continua evolución. La distancia que le separaba de los sistemas regionales se ha ido acortando. Basta con recordar dos notas diferenciadoras de los verdaderos Estados federales, en la actualidad mucho menos acusadas que con anterioridad: 1) la autonomia organizativa de los Estados miembros se ha reducido a poca cosa; hay una ley férrea de homogeneidad política y los ordenamientos internos de los Estados miembros - al igual que los ordenamientos internos de nuestras Regiones- se uniformizan según el modelo institucional del Estado central; 2) la participación de las unidades constitucionales en las funcio- 
nes del Estado central: el mismo fenómeno se produce, a escala más reducida, en el ordenamiento regional. Por lo demás, en los sistemas federales ha perdido el significado originario desde el momento que se ha aclarado que el Estado federal es un único Estado en el que las simples comunidades territoriales estản sometidas, no yuxtapuestas, al poder central.

De todas formas, tanto en nuestro caso como en el Estado federal, la técnica de la distribución de competencias es una de las más difíciles y delicadas. El constituyente tuvo que encontrar el punto justo de conciliación y equilibrio entre exígencias opuestas: de un lado, la exigencia de la rigidez, $\sin$ la cual no hay certeza en las competencias; del otro, la exigencia de la flexibilidad, gracias a la cual se abre el camino a la evolución del sistema. En efecto, es una tendencia inevitable de todo ordenamiento de las autonomías que haya un proceso de descentralización o de centralización según sea el sistema: un proceso centrípeto o centrifugo que introduce un elemento de movilidad en el cuadro, necesariamente rígido, de la distribución de poderes.

Todo esto, por lo demás, fue, en su tiempo, percibido con gran lucidez por los constituyentes españoles. He aqui un testimonio elocuente: "El campo de una autonomía no se mide con el metro de la extensión sino con el de los límites; el campo de la autonomia es aquél que la técnica del contrato de compraventa define como un cuerpo cierto de derechos. No se trata, por tanto, de muchas atribuciones fraccionadas y confusas sino de atribuciones más reducidas e incluso pocas, si es preciso, pero claras y conferidas sin ningún tipo de dudas. El pequeño huerto de un municipio, con el muro de piedras que lo cine, es una autonomia: el monte, una gran llanura - latifundio por extensión y senoria- no es autonomia si desaparecen los mojones de separación y se crea confusiōn. El legislador tiene en sus manos unas tijeras de doble filo: por una parte, debe penetrar en el estatuto de las regiones para evitar que sustituyan al Fstado: por la otra, debe penetrar en las atribuciones del propio Estado. La potestad de legislar pertenece a las Regiones por derecho. En efecto, ¿qué sería de la autonomía regional si -conservando el Estado la facultad de ocupar todo el campo de las autonomías - no le quedase a la Región otra efección que escoger entre ser rebelde y prevaricadora o claudicante y sometida?"

Son palabras pronunciadas en las Cortes por Alcalá Zamora, el gran estadista y legislador, que fue uno de los primeros en perfilar la idea de la región, y mantienen su actualidad en nuestro ordenamiento y en los análo- 
gos. Es preciso entender su espiritu: el legislador se encuentra frente a la obligación de componer los conflictos antes de que surjan, a no ser que se quiera abrir las puertas del gobierno a los jueces, tal y como nos enseñan las vicisitudes de los Estados federales.

Legamos, así, al centro del problema: ¿con qué criterios se efectúa la distribución de competencias? Sostenia, más arriba, que nuestro sistema regional carece de correspondencia exacta con los demás ordenamientos contemporáneos. El criterio con el que se enumeran las competencias en nuestro sistema es el de asignar a la Región unas competencias tasadas. Por lo que puedo saber, este mismo criterio no se utiliza en ningún otro sistema: o se sigue la via de enumerar taxativamente las competencias del Estado central, invirtiendo asf la perspectiva, como ocurre en los Estados federales de más antigua formación (Suiza y Estados Unídos); o, con más frecuencia, se sigue el criterio de la enumeración paralela, diciéndose las competencias del Estado son éstas y las de las Regionales estas otras. De este modo, se enumeran en 1 texto constitucional los dos órdenes de competencias.

En el primer criterio - el de la enumeración de las competencias del Estado central- tiene un origen histórico que no nos interesa. Sí nos importa, en cambio, el presupuesto técnico de esta forma de consignar las competencias: entre las simples unidades territoriales y el Estado central no debe existir ninguin poder intermedio. Todo to que no es de un poder debe de ser del otro. Es el sistema dual anglosajon.

¿Para qué sirve entonces la enumeración paralela de las competencias del Estado y de las Regiones? Los primeros comentaristas de nuestro ordenamiento regional observaron que el sistema de la lista unilateral de competencias es el más racional y el más adecuado al tipo estructural de la Región. Querian decir con ello, que, de todos los posibles sistemas, éste es el que limita más extensamente el ambito de las competencias regionales. ¿Corroboran o desmienten esta creencia los datos del derecho comparado?

Creo que el criterio más difundido, el de la enumeración paralela, obedece a ciertas razones técnicas que surgirán en el curso de mis observaciones posteriores; pero, en modo alguno, supone que se quiera ampliar la esfera de la Región y contraer la del Estado. Esta fórmula de la distribución bilateral ha respondido históricamente, en los sistemas en los que es posible encontrarla, a una exigencia concreta: las materias son recogidas en listas en el texto constitucional con el fin de establecer cuáles deben 
ser atribuidas al Estado central - legislacion, ejecución, jurisdicción-y en cuáles se quiere atribuir al Estado el poder legislativo y a la Región el ejecutivo y viceversa. De esta forma, la Constitución ofrece al legislador y al intérprete una especie de código para discernir las materias que permanecen totalmente en la esfera del Estado de las otras; respecto de las que se prevé una disociación entre la función legislativa y la ejecutiva. Para llegar a este resultado, se prefiere enumerar por separado las materias y las competencias estatales y regionales.

Es sabido que, además de éstas, existen otras razones. Ast, por ejemplo, también la Constitución canadiense (que posteriormente ha experimentado sensibles adaptaciones en la interpretación constitucional en virtud del poder creativo del juez anglosajón) sigue el criterio de la doble lista. Se trata de una opción sobre la que pudo haber influido el propio origen de la carta constitucional, elaborada por el Parlamento de Westminster el pasado siglo. Respecto a Londres, Dominion y Provincias constituian, en aquella época, dos órdenes de entes subordinados: de ahí la necesidad técnica de que el legislador imperial fijase simultáneamente las competencias de la autoridad central y las de los Estados miembros.

Ahora bien, si se considera detenidamente, el sistema de la enumeración paralela es más rígido que el nuestro porque es la misma Constitución la que impone al Estado el ámbito en el que debe moverse. El resultado es que el Estado no puede delegar ni descentralizar en favor de la Región ninguna competencia. Estas estrecheces desaparecen en nuestro ordenamiento.

El sistema de la disociación de la función ejecutiva es, por tradición, el de los países de lengua alemana: Alemania y Austria. El sistema de la autonomía indivisa es el anglosajón. Cuando se prevé, de uno u otro modo, la disociación entre la función legislativa y la función ejecutiva se plantea el problema de la vigilancia, del control y de la coordinación de las actividades delegadas a las unidades territoriales por parte de los órganos centrales. Es un problema que también nosotros conocemos. En cambio, en los paises que crean dos esferas antónomas no se da este problema de la vigilancia. En efecto, al ordenamiento de tipo anglosajón le repugna que los entes autónomos sean sometidos a vigilancia y caigan en una situación de pupilaje. Un criterio análogo parece aflorar en el sistema constitucional yugoslavo. En efecto, el ente-base de la autonomia no lo es ya ni siquiera la República, sino el municipio concebido como un ente de competencia general. 
¿En qué modo se organiza la vigilancia en los ordenamientos en los que la competencia legislativa se escinde de la ejecutiva y, en consecuencia, las Regiones o los Estados miembros ejecutan las leyes federales por derecho propio o bien tras la correspondiente delegación? ¿Pueden interesarnos las soluciones logradas por el legislador extranjero?

A este respecto, es ciertamente preciso guardarse de la sugestión o, peor, de la tiranía de las categorías. Por tanto, únicamente daremos una rápida ojeada a los esquemas utilizados con más frecuencia, prescindiendo de numerosos detalles que no entran en el cuadro que me dispongo a describir. Simplificando, puede decirse que se encuentra generalizada una primera categoria: legislación y ejecución exclusiva de los Estados miembros. En nuestro ordenamiento, existe una categorfa equivalente (legislación y ejecución exclusivas de las regiones), aunque entre nosotros se trata de la excepción y en otros lugares es la regla. Además, uno de los aspectos naturales del federalismo es que haya unas competencias exclusivas del Estado miembro. La misma Constitución española era explícita en este sentido: si no hay competencias exclusivas no hay autonomia regional.

Sé, por experiencia, que los estudiosos extranjeros renuncian a comprender por qué el constituyente italiano se separó de la norma. Pese a ello, yo diria que la diferencia entre el nuestro y los otros ordenamientos es. en este punto, más aparente que real. En efecto, cuando, a diferencia de lo que está previsto para nuestras Regiones, se reconoce la competencia exclusiva del Estado miembro, casi siempre se le deja al Parlamento la posibilidad de establecer, en cada momento, con un acto propio, hasta dónde puede llegar el Estado miembro en el ejercicio de los poderes que le están atribuidos constitucionalmente.

Sentado este criterio, operará la competencia plena del Estado miembro. La cuestión es importante: siempre hay un control preventivo del legislador central. Otro tanto sucede en el juicio de oportunidad con el que el Parlamento compone los conflictos de intereses entre el Estado y las Regiones o entre estas últimas. También esta solución hace fruncir el entrecejo a los estudiosos extranjeros de la Constitución italiana. El límite de los intereses es considerado como una grave limitación de la autonomia regional. Se ha pensado, incluso, en parangonarlo con el veto de las leyes del ordenamiento canadiense, que es un residuo del período colonial. Sin embargo, cuando no existe este control de oportunidad del Pariamento una vez que ha legislado la Región, el control se ejerce antes porque siempre es el Parlamento el que establece, homogeneizando la 
legislación y utilizando plenamente los instrumentos de que dispone, qué límites tienen los Estados miembros aun en el caso de las competencias consideradas exclusivas. En consecuencia, el principio constitucional de la competencia exclusiva existe en abstracto; pues, frecuentemente su límite $\mathrm{y}$, al mismo tiempo, el ámbito dentro del que puede legislar el Estado miembro son fijados, en cuanto a su oportunidad, por el Parlamento; y en la medida en que tales opciones son susceptibles de control en sede jurisdiccional, queda, en último extremo, a la apreciación del juez.

Otro criterio de distribución de competencias deriva de un dato constante: cuando se da la competencia legislativa de la Región o del Estado miembro, la ejecutiva debe seguirla tamquam umbra, Ahora bien, esta categoria es residual en los sistemas que adoptan el criterio de enumerar únicamente las competencias del Estado central: es difícil medir su extensión. Seria útil, por tanto, que se atendiese tambiẻn al contenido concreto de las materias que, en cada caso, se dejan a la competencia del centro o, viceversa, se descentralizan en favor de la periferia del sistema constitucional, sobre todo en aquellos ordenamientos que tienen necesidades económicas y características sociopolíticas en alguna medida asimilables a las nuestras.

¿Respecto de qué materias se admite que puedan tener competencia exclusiva los entes correspondientes a nuestras Regiones? Yo diría que, sobre todo, en el sector de la educación -casi siempre de un determinado grado- cuando existen problemas lingúísticos o cuando hay alguna minoría étnica que tutelar. $\mathrm{Y}$ en algún otro: protección del territorio, urbanismo, fomento de la investigación cientifica, aprovechamiento de los recursos naturales, asistencia social y hospitalaria. Pero es dificil reducir la gran cantidad de detalles que emergen del examen de los textos constitucionales en un esquema o generalización.

Algunas veces se recurre a una fórmula eliptica: "todas las materias de interés local", pero se trata de una fómula desaconsejable desde el punto de vista de la técnica legislativa porque puede abrir el camino al arbitrio đel intérprete.

En Canadá la han utilizado los jueces como soporte de la interpretación evolutiva del texto constitucional, pero lo han hecho con un sentido de moderación que, a menudo, les ha faltado a los intérpretes de otros sistemas. Ahora bien, ies posible que en un ordenamiento como el nuestro, en el que la competencia exclusiva de la Región es excepcional, 
el ámbito de la autonomía pueda alcanzar, por vía de hecho, los niveles del federalismo? En buena parte dependerá de los criterios con que el Parlamento quiera resolver los eventuales conflictos de oportunidad; además, dependerá de la forma en que las Regiones sean, si no asociadas, al menos escuchadas, de una u otra manera, en el curso del proceso formativo de la legislación estatal.

El verdadero sentido de la autonomía regional surgirá de la living constitution. Por ahora, no se puede pretender fijarlo con claridad. La experiencia de los Estados extranjeros nos muestra, en todo caso, que el auténtico federalismo es aquèl que consiente que los entes locales penetren de algún modo en la estructura del Estado, estén representados en ciertos órganos de las Cámaras o sean oídos antes de que el Estado lleve a cabo determinadas opciones que, después, afectarán a su esfera de competencia, tanto más si la comprimen o si amenazan con vaciarla.

Existe, después, una segunda categoría generalizada: legislación y ejecución exclusiva del Estado central. En nuestro ordenamiento se entiende que tiene la máxima amplitud. ¿Cuáles son las materias que se ha reservado aquif casi siempre el Estado central? Defensa, relaciones exteriores, servicios postales, unidad de sistema económico-monetario. Tampoco se puede generalizar en este punto.

En las Constituciones más recientes aparece otro tipo de competencias: las relativas al control de la economia. Puede ser una fórmula omnicomprensiva para atribuir al Estado central muchos de los poderes que, conforme a los otros criterios, no le pertenecerian. Otra categoria más es la de las competencias alternativas. Como aqui se presentan varias figuras de concurso, debo ejemplificar. Una primera variedad carece de paralelo en nuestro sistema: es la competencia que llamaré alternativa. Aludo a ciertos sectores que pueden ser ocupados por el poder central o por el poder local según los casos. Si los Estados miembros no legislan, to hace el Estado central; si el Estado central no legisla, los Estados miembros tienen titulo para hacerlo ellos. Se trata de una categoría nacida de la experiencia de los Estados federales que son el precipitado histórico de una liga internacional que, posteriormente, ha madurado y se ha transformado en un propio y verdadero Estado. En estos sistemas, la legislación de cada Estado anterior a la creación del Estado central se mantuvo en vigor -tal y como ha sucedido inversamente entre nosotros con la legislación estatal- y los jueces la salvaguardaron; incluso, cuando los órganos centrales comenzaron a ejercer sus atribuciones siguiendo, como suele decirse en América, "la regla del pulgar". 
En los Estados Unidos, y en otros paises en los que se sigue el mismo sistema de distribución de competencias, la legislación local se considera válida aunque tenga por objeto materias de competencia federal, mientras responda a ciertos standards de utilidad y no entre en conflicto con la exigencia de una reglamentación uniforme del sector; pues, en este último caso, es el órgano legislativo central el único competente para dictarla.

El artículo 72 de la Ley fundamental de Bonn se inspira manifiestamente en el criterio que acabamos de describir. En virtud del mismo, la federación puede ejercer una competencia concurrente-precisamente en sentido alternativo - con la de los Länder cuando subsistan exigencias de uniformidad y to requieran las condiciones de la vida económica que están por encima de un determinado Land.

Se trata de un ejemplo de racionalización con las categorías empiricas del federalismo anglosajón, por ejemplo, que no es infrecuente en los paises de lengua alemana. Si me he referido a th, pese a que no haya en nuestro ordenamiento esquemas semejantes, es únicamente al objeto de suscitar algunas reflexiones sobre la oportunidad de las soluciones acogidas por los sistemas federales. ¿En base a qué consideraciones o condiciones socio-económicas han llegado a afirmar el juez alemản o el estadounidense que, por ejemplo, ciertas materias requieren una disciplina uniforme? Por evidentes razones de espacio debo prescindir de una investigación semejante, Sin embargo, sí querría sefialar su utilidad: cuando los criterios que en otros lugares han inspirado la legislación del Estado central presentan un engarce seguro y actual con las materias cuya disciplina uniforme debe ser asegurada por nuestro Parlamento, se les podrá tener en cuenta en la medida justa;sin olvidar, por ello, que, en el ordenamiento italiano, el cuadro de las competencias concurrentes está organizado de otra manera y que el legislador central tiene más posibilidades para elegir.

El otro sistema de competencia concurrente en sentido estricto es, precisamente, ef previsto con carácter general por el articulo 117 de la Constitución, Se trata de una fórmula que se encuentra en casi todos los ordenanientos extranjeros: al Estado le corresponde la legislación básica, de principio o programática, y a la Región, la legislaciôn de desarrollo. Cuando opera este sistema en los Estados federales, los Estados miembros tienen como regla la competencia ejecutiva, con exclusión de los órganos centrales. Esta misma solución se ha adoptado también entre nosotros. No obstante, estamos ante una categoría muy dúctil y puede fluctuar entre los dos polos extremos: el simple esqueleto de la ley central o una extensa y penetrante legislación programática. 
Así, por ejemplo, en la Constitución yugoslava se engloban, en este esquema, varias clases de leyes federales: prescindiendo ahora de otras, mencionaremos las leyes-programa y las leyes generales. Las primeras no pueden entrar en vigor inmediatamente; las otras si, pero tienen que ser oportunamente desarrolladas por las Repúblicas autónomas. Ahora bien, en general, alli donde se da prioridad a la competencia exclusiva y plena de la Región no se mira con agrado esta categoría de la legislación estatal de principio. Citemos, por todos, el caso de la España de 1931. Antes de poder dictar los principios directivos de la legislación regional, las Cortes: primero, tenian que requerir un dictamen del Tribunal Constitucional que comprobase la admisibilidad de una disciplina de principio; y. despuis, debian aprobarla por una mayoría de dos tercios. ¡Era más dificil que reformar la Constitución!

Por otra parte, hay ordenamientos en los que la Región está obligada a dictar la legislación de desarrollo dentro de un determinado plazo; dando lugar, si no lo hiciera, a la competencia plena del Estado (tal como estí previsto: por ejemplo, en el articulo 12 de la Constitución federal austriaca). Este último mecanismo de control subrogatorio merece una aclaración. Se supone que el Estado ha dictado ya la legislación de principio y que la Región tarda en adoptar la legislación de desarrollo. Sin embargo, no se considera la hipótesis de que sea el Estado quien. por el contrario, no haya emanado la legislación de principio. En este caso, no se admite que la Región sustituya a los órganos estatales que han incumplido $y$ se comprende el porqué se quiere afirmar el principio de la "prioridad" de la ley central, que también es característico del verdadero y propio federalismo, junto al de la supremacía de la propia ley central en el orden de las fuentes. Las materias respectivamente atribuidas al Estado y a la Región pueden interfarirse; pues bien, cuando surge un conflicto entre las leyes de los órganos centrales y las de los órganos locales, habiendo actuado uno y otro órgano dentro de su propia esfera de competencias (al intérprete cualificado le corresponderá señalar que esto ha sucedido), sera la ley central la que prevalezca.

Las soluciones técnicas del problema de la autonomia varian todo to que se quiera pero, en cualquier caso, permanece invariable el principio de la unidad fundamental del ordenamiento juridico estatal. Es precisamente por esta razón, antes que por cualquier otra, por la que el regionalismo $y$ el federalismo obedecen a las mismas necesidades institucionales.

3.- Alhora bien, hay un problema central que se plantea con relación a todos los esquemas de distribución del poder a los que me he refe- 
rido, que es el siguiente: ¿cómo atemperar la rigidez que debe existir en la distribución de competencias para hacer frente a la disciplina de nuevas necesidades, de nuevas materias? Hemos visto nacer a las Regiones muchos años más tarde de lo que el texto constitucional había previsto. El modelo del ente diseflado por el constituyente, en 1947, nos parece inadecuado para la realidad actual. No se trata de algo casual: en la lista de las competencias regionales falta, por ejemplo, toda mención a la protección del territorio $o$ a la planificación, que son materias de esta fase de la economía más reciente $y$ avanzada.

En los Estados federales, los problemas son aún más graves. En el caso de los Estados Unidos el sistema ha podido sobrevivir, pese a que ha sufrido graves crisis en más de una ocasión, porque la obra prudente e iluminada de la jurisprudencia ha consentido que evolucionara fuera de las trabas del procedimiento de revisión constitucional. En efecto, la carta constitucional, que cuenta ya con dos siglos de existencia, ha sido modificada solamente en unas pocas ocasiones. Con este bagaje, el Estado central, surgido sobre la base de las trece colonias recién llegadas a la independencia, se ha dilatado por el gran espacio de un continente y está en condiciones de controlar hoy una gigantesca economía. Para tener una idea del crecimiento del poder federal bastará con recordar el ejemplo del Interstate Commerce: en un primer momento se trataba de un área limitada y subordinada a las exigencias del mercado libre; después, ha servido para cubrir todo el haz de actividades y fenómenos que pueden interferir en cualquier forma el ejercicio de las competencias centrales. Al ampliarse la materia, la intervención del Congreso se fue extendiendo simultáneamente aunque $\sin$ que se alterara formalmente el esquema đe la distribución de competencias.

En relación a nuestro ordenamiento, puede decirse que está dotado de una rigidez semejante a la de los Estados federales, no sólo en el aspecto đel reparto funcional de las materias, sino también en el de la división territorial. Comencemos entonces por este último punto. ¿Habria algún modo de evadirse de las redes de la subdivisión espacial contemplada 0 , mejor, presupuesta por el texto constitucional? Porque en los Estados federales, en definitiva, hay una menor rigidez a este respecto. En Alemania se habla de federalismo "labil" y esta definición puede referirse igualmente a otros ordenamientos en los que -como en el alemán-basta con el acuerdo del Parlamento central para reajustar las unidades constitutivas de la federación.

Por el contrario, entre nosotros las formas procedimentales que 
gobieman la materia están doblemente agravadas. No sólo se exige la ley constitucional, sino también el parecer de los Consejos regionales y el de la población interesada a través del referéndum. La técnica del federalismo se superpone a la del plebiscito que basta para sancionar las modificaciones territoriales, incluso en los Estados tradicionalmente centralizados como Francia. Es fácil prever que los traslados de ciudadanos a la esfera de una nueva autoridad local serán realizados por el legislador ordinario, trasvasando con cuentagotas provincias y municipios de una Región y otra, con tal de evitar el rigor del procedimiento previsto para el desmembramiento y la fusión de Regiones.

En todo caso, es extraño que ante las instancias del pluralismo social; tan intimamente ligadas a las de la autonomia regional en el pensamiento católico, no haya dado nuestra Constitución más importancia a la posibilidad de organizar grupos o comunidades sociales sobre bases distintas de las territoriales. En el texto constitucional sólo encontramos algunas referencias en este sentido: por ejemplo, la tutelar de las minorias lingü isticas o religiosas. En su tiempo, Karl Renner y otros socialistas austríacos, hicieron del federalismo étnico-cultural su caballo de batalla en el ordenamiento de los Habsburgo. En nuestro ordenamiento, si prescindimos del régimen de los cultos acatólicos, ünicamente queda la norma del articulo 6 de la Constitución: la República tutela las minorias lingüisticas. No es mucho, pero, a mi juicio, basta para atribuir un fundamento constitucional seguro a una comunidad de lengua francesa o alemana que se constituyera como una entidad distinta de las Regiones en las que se hallan las minorias alóglotas. Sin embargo, el hecho es que el selfgovernment territorial continúa siendo considerado entre nosotros como la forma más avanzada de autonomía, una técnica diríase que absorbente en relación a cualquier otra.

Otra via para escapar de las estrecheces territoriales sería también la de crear nuevas estructuras a caballo de varias Regiones y, más en general. la de flanquear las autonomías de carácter territorial con una amplia descentralización funcional de los grandes entes públicos o de ciertos sectores -clave de las industrias del Estado. Las soluciones de este tipo son frecuentes en los programas del socialismo británico que se caracterizan por su acento decididamente pragmático y funcionalista. Harold Laski acostumbraba a decir, con su precision y empirismo típicos, que los ferrocarriles son una realidad mucho más concreta que cualquier provincia de Gran Bretaña. Este autor pensaba en un autogobierno de los productores -más que en el de los consumidores- edificado sobre la sólida base de las áreas administrativas que, a su juicio, no dejarian de federarse entre ellas. 
Este tipo de federalismo le parecia más moderno y más adecuado al Welfare State que la partición territorial del poder vinculada al concepto clásico liberal del Estado abstencionista. Se trata de una intuición técnica y política sobre la cual creo que podremos volver a reflexionar.

Regresaré sobre ella en breve. Entre tanto, será oportuno tener presente la distribución de las materias y de las competencias tal como ha sido efectivamente dispuesta por el constituyente. Las competencias legislativas de las Regiones están enumeradas taxativamente y los intérpretes advirtieron rápidamente que no puedel ser extendidas a través de la integración analógica. ¿Cómo se puede, entonces, tener en cuenta las instancias de la autonom fa regional sin echar mano de la revisión de la Constitución? Nos enfrentamos aquí con serias dificultades a las que el derecho comparado deberá suministrar luz.

Cuando en un ordenamiento federal se trata de aplicar las competencias del Estado central se confia siempre en una norma-clave que comúnmente figura en el propio texto constitucional y está formulada de manera que confiera un amplio margen de elasticidad al poder federal. Por ejemplo, en Austria y en Esiados Unidos, y en muchos otros sistemas. siempre se ha previsto expresamente que la federación tendra todos los poderes indispensables para el ejercicio de sus facultades. En la Constitu- ción yugoslava cambia la fórmula pero el propósito es el mismo: la federación regula la unidad socio-politica de todas las Repúblicas. Suele decirse que son competencias conexas, es decir, estructuralmente vinculadas con las expresamente utribuidas a la federación y se orientan a hacer plenamente eficaz su ejercicio. Junto a éstas, hay otras connaturales al hecho de que la federación es un Estado. Ahora bien, durante largo tiempo se ha dado por supuesto que todo este bagaje de competencias pertenecía también a los Estados miembros de una federación, en la medida en que éstos - a diferencia de nuestra Regiones - venían siendo concebidos como "entes de competencia general", cuando no como Estados en el sentido propio del término. Pero los pretendidos iur majestatis de los miembros son ya simples larvas: aunque en Alemania, bajo el imperio de la Constitución de Weimar, todavia se decfa que era connatural a los Länder el derecho al escudo como signo distintivo de la estatalidad.

De todos modos, hay acuerdo, en muestro caso, en que la Región no es un Estado, ni un ente con competencias generales. Falta, por tanto, el presupuesto para que se le atribuyan las competencias propias de los Estados; y, a mi juicio, debe excluirse la admisibilidad de competencias regionales conexas con aquéllas directamente previstas en el texto consti- 
tucionat. En efecto, el principio de la autonomfa no puede dilatarse más allá de los límites impuestos por la misma naturaleza del ente región. No obstante, la lógica del sistema exige al mismo tiempo que, hasta donde sea posible, no se produzcan excesos en el sentido opuesto, atrayendo dentro de la esfera del Estado, por implicaciones o conexiones, materias que están claramente reservadas a las Regiones. Esta exigencia se advierte con claridad en los ordenamientos federales y en el nuestro no puede ser desconocida dado que la autonom ía regional está prevista y garantizada constitucionalmente.

Puede suceder que, entrecruzandose de hecho Estado y Región en cualq ier punto, venga en consideraciòn una de aquellas competencias estatales que podríamos definir como "angulares", en el sentido de que no se dejan reducir con nitidez dentro del esquema que se utiliza habitualmente para la distribución de competencias y permiten que los órganos centrales bloqueen la vía de la autonomia regional. En tal caso, el legislador se encontrará en la necesidad de conceder alguna salvaguardia a la esfera de atribuciones de la Región;sin vulnerar, por ello, la unidad del ordenamiento estatal. Es una decisión técnica y politicamente difícil. Ayudara a aclarar a qué hipótesis me refiero el recurso a alguna ilustración concreta.

4.- El caso de la integración de nuestro país en las Comunidades europeas y ta disciplina de ciertas materias de competencia regional, no sólo por los tratados internacionales sino tambiẻn por las propias comunidades, cuyas decisiones deben ser inmediatamente eficaces dentro de los Estados miembros, tal vez sca el supuesto más importante. Pensemos en el sector de la agricultura. Si la Comunidad Económica Europea aprueba, por ejemplo, un reglamento que deba tener inmediata eficacia interna, no hay duda de que debe valer también en el territorio de la Región. Incluso, en algùn estatuto regional se pensó en incluir una cläusula en ese sentido $y$, aunque al final no se introdujo, el haberlo hecho no habría alterado en ningún caso los términos de la cuestión.

La Corte Constitucional ha reconocido recientemente la plena legitimidad del Tratado de Roma y, en consecuencia, ha dado pleno fundamento a la eficacia de los reglamentos comunitarios. Otro tanto debe afimarse, segun la Corte Constitucional (me refiero a una sentencia de 1961), de cualquier directiva comunitaria o tratado internacional que necesitara de la intervención del Estado para cobrar eficacia aun cuando afectase a materias de competencia de la Región. Si esto es así, resulta que si bien las Regiones no participan en los acuerdos internacio- 
nales, pues no pueden hacerlo con arreglo a la Constitución, en cambio, el Estado puede "expropiar" sectorts de competencia regional con la ünica condición de que se trate de una materia regulada internacionalmente mediante un acuerdo. Así, pues, es evidente que cuando la Comunicad lleva a cabo un acuerdo o cuando se produce la integración de un tratado, el ente regional cede el paso a un poder supranacional que funciona continuamente $y$ esti en condiciones de interferir, por así decirlo, institucionalmente la esfera de atribuciones de la Region, la cual sufre de este modo una grave limitación. En sustancia, éste es el problema.

Veamos como se ha re.uelto en ordenamientos andflogos al nuestro. Fn muchos casos - yo diria que en casi todos- es el Estado federal el que centraliza la celebración y la ejecución de los tratados. El poder exterior se ha convertido, de hecho al menos, en monopolio de los órganos centrales. En ordenamientos que se asemejan al nuestro en diversos uspectos - la España de 1931 y Austria - se ha sancionado, sin cmbargo, una fórmula de compromiso: la competencia legislativa para ejecutar los acuerdos internacionales corresponde a la Región si la materia es de competencia regional. Pero, se prevé también la devolución de la competencia respectiva a la fecteración si el Land no ejectata el acuerdo internacional (art. 15 parigrafo 7 de la Constitución austríaca). Se salvaguarda, por tanto. el control y la intervención sustitutiva del Estado. En España se hacia otro tanto: no existia un control subrogatorio pero si una forma de vigilancia.

En Italia, no hay nada previsto al respecto ni que la Región pueda ejecutar los tratados intemacionales o las directivas comuritarias ni que et Estado pueda ejerier un control subrogatorio frente a las Regiones. En mi opinión, aquí es evidente la necesidad de aplicar aquella disposición de la Constitución que prevé la tronsferencia a las Regiones de potestades legislativas dentro de los limiter de las competencias de actuación e integración (ultimo párrufo del artículo 117 de la Constitución): pero precisando que la actuación de la normativa central no se reduce a una pura y simple potestad reglamentaria de las Regiones. En otros têrminos, el Fstado se fota de un cuerpo de legislación uniforme pero nexible ciertas normas son r fidas e inderogables, otras pueden ser derogadas, preferiblemente dentro de un plazo determinado, transcurrido el cual la lequislactón estatal regirá en su totalidad.

En relación can las matcrias que son objeto de un tratado internacional o de la directiva comunitaria a ejecutar, el mecanismo de la legislación nexible, le acompañará In delegación a la Región de las funciones 
administrativas estatales. Esta solución es coherente con las instancias de la autonomfa regional $y$, al mismo tiempo, es inatacable desde el punto de vista de la constitucionalidad. El ordenamiento de las competencias no resultará trastrocado. En efecto, la delegación es revocable.por lo que el Estado siempre podrá requerir las funciones transferidas a la Región. Con el requerimiento se produciría pura y simplemente la retirada de la delegación. En consecuencia, no se estaría ante aquel control subrogatorio del Estado frente a la Región que configuran algunos recientes proyectos de ley, cuya base constitucional no es, ni mucho menos, segura. La Constitución sólo prevé el control de legitimidad de los actos de la Región (artículo 125) y -al igual que otras constituciones como, por ejemplo, la austríaca- lat disolución de los Consejos regionales. En consecuencia, se debe considerar que no se admiten otros controles, como el sustitutivo, distintos de éstos. Por tanto, frente a una competencia "angular" del Estado, la autonomía regional será tutelada siempre pero dentro de los límites consentidos por la Constitución. La tutela sería ilusoria si se confiara a un acto del legislador que expone fácilmente su flanco a la anulación por la Corte Constitucional.

En cualquier caso, el supuesto de la delegación muestra cómo puede ser oportunamente atemperada la rigidez del sistema a través del traspaso del ejercicio de algunas competencias. Además, este es un fenómeno más extendido en el derecho comparado de lo que parece a simple vista; pues, junto a la forma de la delegación en sentido técnico, se manifiesta de otras variats maneras. Asi, por ejemplo, en muchos Estados federales se permite que los miembros puedan legislar en los sectores de competencia de la federación cuando ésta lo permita o, viceversa, que la federación pueda legislar tras el acuerdo de los Estados miembros (artículo 252 de la Constitución india; artículo 142 de la Constitución australiana). En ambos casos, el resultado es convergente: o los miembros encomiendan, desde abajo, al Estado tales actividades o es éste el que, desde arriba, se las encomienda a los miembros. Ahora bien, creo que no hay delegación en sentido técnico en ninguno de los dos casos. Es la propia Constitución la que prevé que el legislador central debe abstenerce de legislar y que con un acto de voluntad puede reenviar a la ley de las Regiones. Se trata, pues, de un reenvío a otra competencia que opera solamente en tanto en cuanto asi lo desee el legislador central: no se delega a las Regiones el poder central del Estado sino que se consiente que el legislador central -o los miembros en el caso contrario - renuncien a legislar en su área de competencia. $\mathrm{Y}$ si no hay delegación, tampoco hay necesidad de criterios directivos. Queda únicamente la nuda manifestación de voluntad de uno u otro ente - se entiende que revocable- que es el presupuesto 
necesario para que pueda verificarse el traslado en ef orden normal de competencias al que the he referido.

En nuestro sistema no existen mís instrumentos que el de la delegación de funciones administrativas, si bien es cierto que se ha configurado su régimen de una manera compleja y peculiar a través del doble sistema de la đelegación del Estado a las Regiones y la de éstas a los entes locales. Este paso indirecto, pero necesario, de las funciones administrativas hacia la periferia del gobierno local no esti previsto en estos mismos términos en otros sistemas, del mismo modo que tampoco existe en ellos la figura del comisario del Estado en la Region. Son pues, datos institucionales de nuestro ordenamiento que se compaginan mal con el tipo de Estado federal, si bien se explican perfectamente en el contexto de una tradición de centralización semejante a la francesa, cuyos últimos residuos aún no hemos liquidado totalmente.

Simplificando, hay que decir que en relación con la delegación de funciones administrativas existen dos modelos: uno, et más conocido, es el alemann; el otro es el representado por la Espana de 1931 y por Austria.

El modelo alemán es radicalmente distinto al nuestro. En Alemania ha imperado siempre et principio según el cual los Estados miembros ejecutan las leyes federales se trata de una competencia natural de los mismos. Existe una antigua y fecunda costumbre de localismo administrativo: la federación es quien legisla y el Land es quien dispensa cotidianamente al individuo la administración de las leyes. Justamente por estos motros, no dudo en hablar de una soberania administrativa de los Estados. Es cierto que hay unos controles que son indispensables. pero la federación sólo puede impartir instrucciones generales y exclusivamente a las autoridades supremas del Land. Cuando éste se niega a obedecer es el Senado federal -en el que las Regiones hablan por boca de sus propios delegados - el que asume el control;desaparece el agente del Estado en las regiones y la coordinación entre el centro y la periferia de la Administración es confiada al Senado, órgano que cumple mejor que en cualquier otro ejemplo de federalismo la función institucional de colegio de las Regiones:

Sin entrar en los detalles, he de decir que en la base de toda esta construcción se encuentra un sentido diferente de la autonomia, solidamente enraizado en el mundo de lengua alemana. De él todavia podemos hallar algún reflejo ocasional en aquellas de nuestras. Regiones que histó. 
ricamente patenccieron en algún momento al Imperio austriaco. En esa concepción, antes aún que la autonomia legisłativa llega al cuerpo local la función administrativa; así, ta burocracia profesional se conecta - en las raices de la sociedad política - con los elegidos por el pueblo; la actividad administrativa se ajusta en la mayor medida posible a los métodos de la jurisdicción, vivificándose e iluminándose, de este modo, con un recto entendimiento de la ley. Es así como el principio del Estado de Derecho adquiere un significado concreto, En el siglo pasado, cuando tas instituciones del Estado liberal todavfa se hallaban en uns fase embrionaris. los juristas alemanes habian captado ya el significado esencial del sitf-government. Por eso, nos advertían que no importa que ei texto cons acional haya establecido un régimen parlanentario si luego el poder eje cutivo, siervo de las Cámaras, ariende a los deseos del tirano frente a los ciudadanos: el centralismo administrativo y la burocracia irresponsable apartan al individuo del ejercicio maduro y consciente de sus derechos politicos. Guido de Ruggero ha dejado una interpretación magistral de estas doctrinas. Quién podria negar su actuatidad si es cierto que la autonomia regional debe avanzar por el cauce de la gran tradición đel Estado de Derecho?

Tenemos despućs cl modelo austríaco y el espanol que son análogos al nuestro. pues utilizaban ai presidente de la región como un doble órgano del Estado y de la Regióa, responsable tanto ante el gobierno como ante el Consejo regional. Esta solución está recogida en el articulo 121 de nuestra Constitución y en muchos estatutos regionales. Sin embargo, como ya he dicho, en los Estados federales no existe el comisario del Estado ni, tampoco, la figura del control de oportunidad; por eso, la coordinación debe ser realizada en los vértices del sistema y tiene que estar disciplinada necesariamente en la Constitución. Nuestro texto fundamental deja sin regular todas estas cuestiones mientras que las Constituciones federales contienen una detallada regulación de las mismas; de otro modo habrían faltado a su finalidad.

5. - Ahora bien. cuando se habla de coordinación en el vértice, se está postulando un doble orden de factores institucionales: la desaparición de los residuos del Estado centralizado - y de la figura del comisario que, en el fondo, no es más que un superprefecto regional-y, por otra parte, la presencia de ciertas estructuras institucionales que no existen entre nosotros: un Senado que sea una verdadera cámara de las regiones: un aparato ministerial reducido al máximo; agencias y entes organizados de diferentes maneras pero sujetos siempre a la vigilancia del poder central; una serie de ministerios que sean órganos de administración activa 
en las materias que recuen en la competencia exclusiva de la federación y otra de ministerios que sean órganos de mero control.

Se trata de un cuadro apenas esbozado que no puedo desarrollar más, pero aqui se toca el corazón del federalismo. Es evidente que no st da en nuestro sistema, ni puede ser creado de un plumazo, salvo que so modifique todo el escenario de las autonomias. No obstante, esto no significa que no haya sitio en el ảmbito de la Constitución para un sistema regional cada vez más próximo al federalismo. En este sentido, la experiencia extranjera también nos muestra algunas soluciones: se trata únicamente de considerarik con la debida cautela. Un posible primer criterio es el de la especializución de los órganos internos de las cámaras sobre la base de la pertenencia a las regiones de los elegidos: diputados y senadores se retinen por grupos según la región en la que han sido elegidos.

Esta solución es adoptada en el sistema de monocameralismo diferenciado - que, en el fondo, es un pluricameralismo sustancial- de Yugoslavia, en el que los consejos regionales se forman dentro de la cámara y, también, en otros sistemas en los que no existe una descentralización institucional como la nuestra.

Por ejemplo - cito el caso inglés que, como sucede a menudo, es inimitable pero no por esto carece de interés- en Gran Bretana existe una especie de subparlamento para Escocia. Para la aprobación de las leyes aplicables a esta región se sigue un criterio procedimental distinto del que se utiliza para la legíslación ordinaria: el proyecto de ley es tramitado en primera y segunda lectura por el comité escocés, que reùne a todos los miembros elegidos en Escocia y a otros representantes de la Cámara. de forma que refleje la composición política de la asamblea. Tras la segunda lectura, el proyecto de ley es examinado y aprobado solamente por los diputados escoceses y, después, casi siempre es ratificado por el plemum de los Comunes. Gracias a este régimen procedimental se ha ido fomando una legislación "escocesa" diferente del resto de la legislación de Gran Bretaña. Con respecto al poder ejecutivo, se ha seguido un criterio análogo. Hay un ministerio especializado y un secretario de Estado para Escocia, cuadros burocráticos completos cuya competencia se superpone ratione materiae con la de las otras ramas del gobiemo. Ahora bien, icòmo se puede adoptar un sistema de este tipo en un ordenamiento como el nuestro en el que el principio de la autonomía comporta ta creación de diferentes órdenes de cuerpos legislativos? El criterio de la división de los diputados y senadores segun las regiones a las 
que pertenecen -posible en Francia, pues los miembros elegidos al Parlamento en cada una de las regiones creadas últimamente se reúnen junto al prefecto, órgano ejecutivo y agente del poder central- para nosotros sería solamente una complicación inútil y rebuscada de las estructuras existentes.

¿Qué decir de la propuesta de corregir nuestro bicameralismo acentuando el perfil regional del Senado? No cabe duda de que el Senado tal como esta estructurado hoy constituye un duplicado do la Cámara; por eso, sería oportuno modificar no sus funciones, sino su composición. No obstante, los margenes que deja al respecto el texto constitucional son reducidos. No hay un sistem: federal en el que no esté previsto directamente la Constitución el criterio de representar a los mienbros en el Senado. En cambio, en nuestra carta constitucional se dice solamente que el Senado es elegido sobre una base regional, A mi juicio, no parece que pueda afirmarse que esta regla autoriza la elección indirecta de los senadores, en vez de serlo por el cuerpo electoral, pongamos que por parte de los consejos regionales, tal como se pensó, en un primer momento, en la Constituyente. Por lo demás, fuera del caso de la Alemania occidental, en la mayor parte de los mismos Estados federales, aun cuando todos los miembros tienen asignado un igual número de escaños en el Senado, sacede que los miembros de la Camara alta son elegidos directamente por el pueblo, del mismo modo que los diputados. Si, en cambio, el criterio diferencial est $\hat{\mathfrak{l}}$ en ampliar o restringir las atribuciones del Senado respecto de las de la Cámara, es evidente que sólo se podria conseguir este resultado a cambio de modificar la Constitución. ¿Cuáles son, pues, los otros posibles reajustes del sistema que no implican necesariamente la revisión constitucional?

6.- Ante todo, está la praxis informal de las consultas entre el Fstado y la Región, solución que fanciona bien en los sistemas anglosajones, mís proclives al enpirismo que los continentales. En nuestro caso, siempre se ha asegurado que se organizaria de forma permanente, Por fanto, no queda sino prever órganos consultivos interregionales - en la medida cu que la ley y los reglamentos intemos de las Cámaras lo consientan - e, incluso, su dictamen vinculante con tal de que se observen dos criterios que no pueden faltar en un organismo de cooperación: colegialidad e igualdad entre las Regiones. Frente a la tendencia que prevalece en nuestro sistema, justo la opuesta a la señalada, seria conveniente introducir innovaciones en este sentido. Pensemos en las consultas privilegiadas de algunas regiones previstas en el ordenamiento vigente: el derecho de los presidentes regionales a participar en las reuniones del consejo de 
ministros y el derecho de la Regiôn a elaborar normas en algunas materias o. por ejemplo el droit de régurd de Cerdenta antes de la celebración de determinados acuerdos internacionales que afecten a stus intereses.

Se trata de tura singularia, de privilegios que no sirven al objetivo que me estoy refiriendo porque no pueden ser generalizados. $Y$ no vale argumentar que el principio de igualdad entre las Regiones no está sancionado institucionalmente en nuestro ordenamiento en la meihda en que se ha querido crear entes a las regiones de estatuto especial y después a las otras. En definitiva, cstamos ante una desigualdad relativa al igual que es relativa la iguallad de los Estados miembros en el ordenamiento federal. Del mism - modo que hay ciertas obligaciones que aun sin estar expresamente precistas en la Constitución o en los estatutos (por ejemplo, la obligación de respetar los tratados internacionales) se extienden automaticamente a todas las regiones, asi tambićn deberán extenderse automáticamente a todas las regiones los derechos. Naturalmente, para configurar un organismo de este tipo sería necesario tener en cuenta su conexiòn con las bases constitucionales. Por sjemplo, la reserva de ley sobre la orgunización de la presidencia del conscjo de ministros ofrece un válido punto de apoyo: et mesanismo de las consultas Estado-regiones puede ser articulado en la arisma ocasion en la que se procede al reajuste de la administración echiral. Por atra parte, hay que tener presente otra nota recurrente de la experiencia extranjera los problemas de las consultas no podrain ser resueltos completamente hasta que la estruetura del vèrtice del Estado no se acomode a las exigencias de la autonomia y de la descentralización.

Entre nosotros, la cuestión afecta de cerca al reordenamiento de los ministerios. En otros lugares, en donde existe un federalismo avanzado, afecta a la propia forma de gobierno. El esquema del gobicrno colegiado suizo, por ejemplo, o la solución monocrática americana nacieron y se justificaron en el contexto del Estado federal. En cambio, el sistema de gobicrno parlamentario, aunque en su conjunto ha funcionado bien, ha tenido que ser adaptado a los Estados federales, basculando casi sicmpre sobre el criterio de la preeminencia del jefe del ejecutivo. Por eso, en Alemania $y$ en los Estados federales anglosajones, el régimen parlamentario se ha transformado en un régimen de canciller o de primer ministro. Por el contrario, en Estados Unidos precisamente este problema de la organización del poder ejecutivo y de sus relaciones con los Estados miembros si bien no ha llegado a producir una crisis del sistema, si ha servido para poner de manifiesto sus limites y carencias institucionales. La ley de tendencia del federalismo apunta a la existencia de un amplio y fluido número de agencias, entes mal definidos, que es necesario reabsorber de 
Ilgün modo en las estructuras del vértice del Estado. Cuanto más se reduce la organización del Estado central, más crece el número de estos entes, a los que el Estado federal sólo puede vigilar pero no administrar directamente.

En América, el Presidente se ha visto obligado recientemente a declarar, on un mensuje al Congreso, su voluntad de reformar radicalmente la estructura del poder ejecutivo. Permanecen ủnicanente los cuato ministerios tradicionales (Exteriores, Tesoro. Justicia, Defensa) y se crean ex nowo otros cuatro ministerios, que de aquí a poco habrín de absor a a todos los demás entes. Si el proyecto fucre aprobado, la estructura il presidencialismo resultoria profundumente modificada; pues, en cail uno de estos ministerios se prevén unos directores regionales que residiran en otras tantas áreas de los Estados Unidos.

7.- Me he ocupado hasta aqui del primer aspecto del tema que me habia propuesto. Ahora bien, la investigación queđaria incompleta si no iuviese en cuenta el otro fenómeno, hoy de importancia capital para el federalismo: me reficto a la cooperación entre las unidades constitutivas de la federación, la cooperación de las regiones entre sí $y$ entre ellas y el Estado.

Se trata de una tendencia irreversible del federalismo actual. Se ha pasado del "sistema dual", al que me he referido antes, a otro de federalismo cooperativo. Al sistemal federal, cuyo fin se ha preconizado por considerarse que no podria plegarse a la necesidad de la intervención del Extado en la economfa, ha constguido sobrevivir evolucionando, tal y como be señalado mis arriba. De ahif ha resultado una nueva figura: el Fstado cooperativo. Han contribuido a influir sobre este desarrollo varias circunstancias: el paso de la sociedad agricola a la industrial, la continuidad de ciertos fenómenos económicos (por cjemplo, la generución c irradiación de la energia hidrocléctrica, que no se puede reducir a una mera competencia federal o local), la programación y planificación integrada de ciertas areas del territorio que interfiere en dos o más unidades tradicionales. Estos factores también lian comparecido ya en nuestro cuadro social; por ello, la experiencia extranjera no puede dejar de interesarnos seriamente.

Cuando se discute el reajuste de las estructuras administrativas estatales, se plantea el problema de regionalizar los entes del Estado. Se dice que nos encontramos ante una opción importante: dejar estos entes al Estado, es decir, dejarlos sin modificar, o regionalizarlos. Pues bien, la 
experiencia de los Estados federales nos enseña que hay una tercera solución, la de crear entes mixtos del Estados y las Regiones.

La propia Corte Constitucional, en la sentencia dictada en el caso de las transferencias a las Regiones de competencias en agricultura, se ha referido de manera incidental, pero con claridad, a esta eventual línea de desarrollo. Es un primer y autorizado reconocimiento de la necesidad de que la tutela de los intereses transregionales no sea confiada únicamente al Estado. ¿Qué indicaciones podemos extraer de todo esto?

Si observamos la experiencia extranjera, encontramos una enorme variedad de formas de cooperación. Por eso, no voy a describir su tipologia completa: tampoco pretendo prever la tipología de entes que podrian corresponderse con los extranjeros. Ciñéndome a lo esencial del fenómeno, señalaré que hay un primer modelo: el que nos of recen las recientes enmiendas a la Constitución alemana. En esta Constitución se han introducido nuevas reglas - todo un título - específicamente referidas a las competencias comunes de la federación y de los Länder, que presentan un gran interés: en efecto, afectan a la ampliación de los institutos superiores, a la mejora de las estructuras agrarias, a la programacióncuadro $\mathrm{y}$ a la programación regional $\mathrm{y}$ a la promoción de instituciones $y$ de investigaciones, de interés regional.

Por lo demás, en la España de 1931 existian formas análogas. En Austria, cuando la cjecución de un reglamento o de una ley estatal deba rcalizarse por varios Estados miembros concertadamente, se prevé que estos han de concluir un acuerdo al objeto de hacer operativas la ley y las directrices estatitles. Si este acuerdo no se produce, interviene el Estado. En general, éstas son formas de cooperación necesaria, pues detrás de cllas aparece siempre la figura del control sustitutivo del Estado.

Un segundo modelo es el de los acuerdos entre las unidades constitutivas de la federacion. Tiene varias subespecies: en efecto, estos acuerdos pucden ser utilizados para crear entes que, a su vez, dan lugar a otras nuevis figuras; en la práctica, tantas cuantas quieran crear los legisladores.

En Alemania, el primer modelo - el de las competencias comunes del Estado federal y de los miembros- tuvo que ser previsto en una especifica regla constitucional al objeto de consentir la injerencia de la federación en la esfera institucionalmente reservada a los Länder, esfera que en un ordenamiento como el alemán es residual $y$, en todo caso, sin duda alguna, más amplia que la de nuestras Regiones. Entre nosotros se 
podria conseguir el mismo resultado por medio de la ley ordinaria. En efecto, basta con este medio técnico para institucionalizar un sistema de colaboración entre el Estado y la Región. La misma ley que puede devolver a las Regiones funciones normativas-integrativas o delegarles funciones administrativas, puede configurar, con mayor razón, un régimen de cooperación. Dos campos a tener en cuenta a estos efectos son el de la investigación científica y el de la educación universitaria.

En cambio, es bastante más problemático introducir en nuestro país el modelo de los acuerdos entre las Regiones y alguno de los entes creados en virtud de tales acuerdos. En efecto, si se llevase a cabo en nuestro ordenamiento tal sistema de cooperación nos acercaríamos cada vez más al modelo del Estado federal; pero, entonces, el problema que habría que aclarar sería el del fundamento constitucional de estos fenómenos. En los ordenamientos federales, los acuerdos a que me refiero están previstos expresa o tácitamente. Recuerdo, por ejemplo, las formulas del artículo 1. sección 3 de la Constitución de los Estados Unidos; del artículo 7 de la Constitución Suiza; del artículo 107 de la Constitución austriaca. En el ordenamiento suizo se ha desarrollado una práctica de cooperación intercantonal a través de concordatos. En el texto constitucional yugoslavo se habla, incluso, de una cooperación institucional entre las repúblicas federadas y los municipios. En Alemania estả previsto que los Lander estipulen tratados con potencias fronterizas y a fortiori se considera que pueden concluir acuerdos entre ellos.

¿Por qué faltan en nuestro ordenamiento unas previsiones semejantes a éstas? En la Asamblea Constituyente, el profesor Mortati y otro ilustre legislador, el profesor Perassi, plantearon el problema. Uno y otro sugirieron que en el Título quinto de la Constitución se introdujese una cláusula especifica que habilitase a las Regiones para gestionar funciones administrativas individualmente o por medio de un consorcio formado por ellas. El ponente, el profesor Ambrosini, dijo que tal regla no era necesaria porque debía considerarse implicita en la economia del texto constitucional. En cambio, más tarde, con el proyecto de ley número $1.602 / \mathrm{A}$, en su articulo 45 , encaminado a modificar la ley Scelba, pero que después no fue aprobado, se quiso introducir la prohibición expresa de que las Regiones constituyeran consorcies entue ellas. Uno de los estatutos regionales prevé la posibilidad de crear consorcios y sociedades interregionales. Se trata del estatuto emiliano. He trabajado en él personalmente, y puedo recordar que cuando se pensó, en la Comisión del Consejo regional, incluir esta cláusula, se queria resolver asi un problema interno de competencia de la Región. Se quería que todo eventual acuerdo 
o consorcio con otras Regiones, celebrado por el Presidente de la Región o por la Junta, fuese aprobado por el Consejo regional. Con la aprobación del Estatuto, todo esto se transformó en ley del Estado, pero ante el silencio de la Constitución ¿qué conclusiones se pueden deducir respecto a las demás Regiones del caso de la Emilia?

Ante todo, he de precisar que aunque existiese una previsión constitucional de esté tipo, el problems no estaria resuelto; en efectu, no bastaria con que la Constitución estableciera que las Regiones pueden concluir acuerdos porque ¿cual seria entonces it régimen de la distiplina de esos acuerdos? ¿Cuál sería su etiera de aplicación? ¿Qué órganos serian los competentes para estipuiarlos? En otro orden de cuestiones, si ésta fuera materia de competencia estatutaria, con respecto al eventual

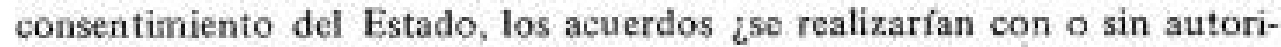
zación del Parlamento o de otro órgano central? Por lo que hace a la relación entre el acuerdo y el sistema de fuentes, dispuesto en el mismo acuerdo. ¿podría ser contradicho por posteriores leyes regionales o estatales? ¿Cuáles serian -por últime- los controles sobre las normas puestas por los acuerdos y cuáles los remedios jurisdiccionales para el caso de imcumplimiento?

Como se ve, estos problemas permanecen abiertos y parece que no podrán ser resueltos ni siquicra con una ley del Estado si se tiene en cuenta que la ausencia en la Constitución de la previsión de la posibilidad de tales acuerdos significa que las Regiones no han sido habilitadas para celebrarlos. Ahora bien, antes de inclinarme por tal tesis, yo me preguntaría dónde se encuentra el fundamento sustancial de estos acuerdos; en este sentido, creo que puede plantearse la cuestión en estos términos: ¿qué se pretende?, ¿que el acuerdo sea un modo de ejercer algunas de las competencias de la Región o que sea solamente una expresión de su personalidad juridica: En el primer caso, la figura tendría una base más bien incierta. Si el acuerdo entre las Regiones fuese un modo para que varias de ellas ejercieran su propio poder, no unilateral sino conjuntamente, entonces podría darse el caso de que se eludiera el control ideato para ejercerse en relación con las formas típicas de actuacion del poder regional. Por el contrario, en aquellos casos en los que el acuerdo no produzca otro efecto que el de obligar a la Región a emanar o no un cierto acto $\sin$ que con cllo se dicten normas que sustituyan a las regionales y sin que sé creen órganos que sustituyan a las regionales, ¿por qué negar, entonces, esta posibilidad?. ¿tal vez porque la Región no es una persona juridica? No obstante, si es éste el único fundamento seguro para los acuerdos en el texto de la Constitución, será necesario, para que sean 
coluerentes con el cuadro constifucional, que todos los mecanismos de cooperación se construyan de tal modo que no desvien el poder decisorio de las Regiones fuera de las sedes competentes.

Veamos ahora, más de cerca, los modelos que nos sugiere el derecho comparado. La experiencia nos permite establecer que el Estado nunca deja de comparecer en todos estos fenómenos de coopleración entre las Regiones. Su consentimiento se requiere siempre y no se limita a participar como órgano autorizante sino que, incluso. pasa a ser miembro de la organización. De ahí deriva una relación trilateral, tendiendo el modelo de l. cooperación entre el Estado y la Región, y el de la cooperación inter geonal a confundirse, en la practica. en un inico fenómeno de cooperación. ¿Qué ventuja tiene la participación del Estado central en cl acuerdo si en tantas ocasiones puede dar lugar a una relación claudisante para las regiones, ya que el Estado interviene por medio de una ley que at uismo puede suprimir unilateralmente, tal conso ocurre en los Estados Unidos? Evidentemente, el compromiso financiero del poder central; ahora bien, en muchos sistemas de financiación estatal se presenta como una contribucion ordinaria pero condicionada. Se da un sistema de condicionamiento e incentivación reciproco en los gastos: el Estado federal contribuye con las Regiones con tal de que èstas se comprometan a realizar un cierto pasto dentro de un determinado lazo: ademis, desde el momento en que la propia federación participa en esta relación, abre a los miembros de este organismo, o bien a las partes del acuerdo, 0 a las instituciones creadas por el acuerdo, la posibilidad de penetrar en la esfera reservada a la federación.

Esto supuesto, fuera del tipo de sociedad privada prevista en el estatuto emiliano, el modo de cooperación más extendido en el extranjero es al de los entes públicos fundados sobre la base de la representación paritaria de los Estados miembros interesados, entes dotados de funciones en unas ocasiones decisorias y en otras solamente preparatorias, consultivas auxiliares. Hay quien dice que el recurso a estos entes es una solución marcadamente burocrática. Se trata de una opinión tal vez excesiva: en efecto, las grandes agencias que constituyen la categoria más importante entre dichos entes gozan de una pujante vida autónoma pero, pese a ello, continúan sujetas al control politico. Así, por ejemplo, en Estados Unidos han surgido organizaciones gigantescas, como la de la Autoridad del Puerto de Nueva York, que están conectadas siempre con el poder político que puede vigilarlas e, incluso, ejercer el derecho de veto sobre las decisiones de los consejos de administración de esas organizaciones. En cualquier caso, ya no quedan trazas del recelo alimentado desde el 
siglo pasado por cuantos temian que estos organismos interregionales pudieran rivalizar con las autoridades centrales y comprometer, de esta forma, la unidad del Estado federal. En Alemania, y en Suiza, según se ha constatado recientemente, existe un denso estrato de instituciones que fluctúan entre los Estados miembros y la federación. Este hecho no suscita ninguna alarma para el futuro del federalismo: unicamente se pretende evitar que, a través de la cooperación, se vacíe a las unidades territoriales de sus funciones características, se creen sociedades leoninas o bien $-\mathrm{y}$ esto es lo más frecuente- que se altere la fisionomia constitucional interna de los miembros, sup'rponiendo el organismo técnico a los cuerpos politicos elegidos por el p'seblo.

Se puede afirmar, incluso, que los modelos de la cooperación responden plenamente a las necesidades de la econom ia planificada y al espiritu de nuestro tiempo. El interés que despiertan en Francia es un signo evidente. Las regiones han sido creadas por el legislador francés sobre todo para que cooperen entre ellas, si bien dentro de los límites en que existen como entes autónomos. El artículo 4, párrafo segundo de la ley de 7 de julio de 1972, dice: "Dos o más entes públicos regionales pueden estipular acuerdos para el estudio, la financiación y la realización de las infraestructuras comunes para la creación de institutos de común utilidad". Para retomar el caso más conocido, añadiré que los entes surgidos de ia colaboración se han construido generalmente sobre la base de ciertas cláusulas-tipo. Dichos entes han de disponer de todos los poderes necesarios para el ejercicio de sus funciones no incompatibles con la Constitución central y con la Constitución local. No tienen poder de imposición fiscal pero pueden recaudar el coste de los servicios; pueden emitir obligaciones. El control político se ejerce por las autoridades locales y por las del Estado federal de la forma que he señalado.

Ahora bien, ¿cómo podría aplicarse entre nosotros este vasto y sugestivo cuadro del federalismo cooperativo? Me voy a limitar a unas rápidas observaciones para perfilar el problemis.

Ciertamente, sería posible instituir las figuras simplificadas de las comisiones interregionales paritarias, pero tendrian funciones de estudio y preparación no decisorias. El problema podría ser el de ver si pueden crearse o gestionar servicios administrativos en las grandes áreas regionales: aquí, ante la falta de una autorización expresa de la Constitución. permanece la duda de la que ya he hablado. No obstante, en nuestro caso mucho más que en otros Estados, el problema podría afectar a las materias de competencia estatal. Es decir, si en otros Estados el Estado federal ha intervenido en la esfera de los Lãnder a través de la coopera- 
ción. entre nosotros el problema se podría plantear hasta cierto punto al revés: en cualquier caso, nos conduciria una vez más a la mitad del camino que lleva hacia las soluciones del federalismo. Me refiero a un mecanísmo de cooperación que actúe en los sectores de competencia estatal; un ente estatal pero con participación regional. Se trata de un planteamiento inverso respecto al de las participaciones estatales.

El medio técnico es aquí la ley ordinaria del Estado, pero una ley que prevea la representación de los entes locales, así como la utilización del instrumento de la delegación a todas las regiones, provincias y municipios comprendidos en la zcna en la que el ente debería actuar. También deberá introducir los wecesarios criterios de flexibilidad administrativa, si bien sin contradecir las reglas constitucionales que deben gobernar el ejercicio de la actividad administrativa. Por lo demás, este esquema se presenta como el más adecuado para los legisladores extranjeros. En más de un ordenamiento se piensa en regionalizar ciertos ministerios descentralizando funciones a nivel local, aunque sobre la base de consorcios o agencias que hayan formado las Regiones entre si. Por eso. el acuerdo de las Regiones determina, en cierto modo, la esfera de la competencia funcional de los órganos periféricos del Estado.

Sin embargo, el esquema del consorcio entre entes locales, al que estamos habituados en Italia. no sirve para este propósito, a no ser que se rehaga desde el principio. En los trabajos preparatorios del estatuto cmiliano se dijo: utilizamos ta palabra consorcio porque de otro modo no nos entenderíamos; sin embargo, no podemos recoger el esquema técnico del consorcio municipal o provincial. Por lo tanto, es preciso un proyecto normativo de la cooperación que sea orgánico y funcional. Las iniciativas no han faltado y, a mi parecer, revisten el máximo interés. Recordaré una de ellas para concluir.

He visto un interesante proyecto de ley de la presente legislatura, el nùmero 602 , que configura el Ente comunidad del Garda y abarca un determinado ambito territorial situado entre varias Regiones y provincias. Este Ente, cuya naturaleza, por lo demás, no se define, tiene sin embargo varias counpetencias según el proyecto de ley citado: competencias prepanatorias en materia urban istica y económica, atribuciones administrativas delegadas por el Estado en materia de turismo, industrias hoteleras, urbanística, navegación interna y puertos lacustres, pesca y patrimonio piscícola, concesión de playas. Además, posee funciones consultivas en relación con el área comprendida en la cuenca del lago y goza de un genérico poler de iniciativa. En algunos casos se deberá proveer a la ânanciación con una contribución ordinaria del Estado en la medida, 
creo, de cien millones amuales. Un ente como sste integraría todos los ingredientes del federalismo cooperativo. Desde la perspectiva de las competencias y de la dimensión territorial, se dan aquí todos los elementos de un ente interrregionalt inchiso, aunque se pensara en hacerio coincidir solamente con un ärea de las Regiones interesadas. Sin embargo, en la ponencia del proyecto de ley mencionado $s$ habla de comprensorios. Por tanto, este ente destinado a operar en el territorio de varias Regiones es considerado como un ente menor respecto a la Región.

Se diria que, en este caso, nos encontramos ante una ficción a la que et legislador ha tenido que recurrir, ficción afortunada si sirve para crear. sin violar la Constitución, un nuevo organismo cuya necesidad es evidente. Pero en este caso, y dado que el ente comprensorio debería ser delegatorio de las funciones administrativas del Estado, ¿por quẽ no delegar dichas funciones simultáneamente a todas las provincias y municipios interesados, en vez de delegarlas al comprensorio en cuanto tal? Es cvidente que aquí se pretende legitimar una nueva criatura institucional de nuestro ordenamiento. De este modo, se ha querido descartar la formula de consorcio interregional (que no esta previsto en la Consticución y estaria expuesto, a mi juicio, a una posible impugnación del Estado) y utilizar, en su lugar. I del comprensorio: que se sitủa dentro del esquema de entes locales al que se refiere el artículo 118 de la Constitución. Por lo demás, el comprensorio tiene un primer reconocimiento en los estatutos especiales en lo que se refiere a los objetivos de la planificación.

Ahora bien, si esto es asi, yo aun daria un paso más hacia adelante. Si es la ley del Estado la que ha de organizar, fundamentar y delimitar la autonomia local, nada impide que los municipios y las provincias (no se puede hablar de Regiones, pues en tal caso habia que acudir forzosimente a una ley constitucional) sean autorizados por ley del Estado para ceicbrar acuerdos entre ellos con el consentimiento de las Regiones interesadas, pudiendo incluso ir más allá del territorio de éstas. Igualmente, nada impide que les autorice para crear un tipo de entes respecto de los cuales la ley del Estado podría asegurar el fundamento, establecer el modelo y dictar el regimen necesario. De esta manera, este federalismo cooperativo. este sistema de las autonomias consociativas, naceria desde abajo. Pero zes importante esta circunstancia? El federalismo puede nacer perfectamente desde abajo. Sin embargo. lo interesante es que el legislador encuentre los medios adecuados para acomodar la rigidez del sistema constitucional a las necesidades del momento; si asi se hiciese el encuentro, no digo con los Jetalles, sino con el espíritu del federalismo, tal como éste existe en los paises que nos son más próximos en el seno de la Comunidad Económica Europea, sería pleno y prometedor para el futuro. 